\title{
The Effect of Dynamic Assessment on L2 Grammar Acquisition by Iranian EFL Learners
}

\author{
Mojtaba Kamali*, Mehdi Abbasi, Firooz Sadighi \\ English Department, Islamic Azad University, Shiraz Branch, Shiraz, Iran \\ Corresponding author: Mojtaba Kamali,Email: m_kamali3156@yahoo.com
}

\section{ARTICLE INFO}

Article history

Received: January 01, 2018

Accepted: January 29, 2018

Published: January 31, 2018

Volume: 6 Issue: 1

Conflicts of interest: None

Funding: None

\begin{abstract}
This study investigated the effect of dynamic Assessment (DA) on the acquisition of L2 grammar by EFL learners. The focus was on teaching Conditional Type II, or Unreal Conditional, which is a difficult structure for language learners to acquire. To this end, two intact classes of intermediate EFL learners, each consisting of 23 male students were assigned to control and experimental groups. They were pre-tested and post-tested (immediately and delayed post-test) using a written grammaticality judgment task. Multivariate Analysis of Covariance (ANCOVA) was run to analyze the data. The results revealed that the experimental group significantly outperformed the control group $(\mathrm{p}<0.05)$ on both immediate and delayed post-tests. The findings point to the advantage of implementation of DA in L2 grammar instruction in classroom contexts.
\end{abstract}

Keywords: Dynamic Assessment, L2 Grammar, Sociocultural Theory, Mediation, Second Language Acquisition

\section{INTRODUCTION}

Dynamic Assessment (DA) refers to integrating instruction and assessment in an attempt to present a person's ability originated from the concept of Vygotsky's Socio-Cultural Theories (SCT) and its "Zone of Proximal Development" (ZPD). According to Vygotsky (1962), learners have two levels of performance: their current level of development or $\mathrm{ZAD}$, and their potential level of development, or, in Vygotsky's terms, the ZPD. The former refers to the learner's ability to perform without the external help, while the latter means that the learner can move from the existing performance level to the next level of development through guidance and assistance (Bavali, Yamini, \& Sadighi, 2011). One of Vygotsky's colleagues, Luria (1961), compared "statistics" with "dynamic" methods of assessment. As Luria noted, statistical assessment, though grounded in sound psychometric principles, inappropriately considers that a person's solitary performance on a test represents a complete picture of the individual's capabilities. On the other hand, DA argues that an individual's potential requires two additional pieces of information: the individual's performance with the help of others and the extent to which the individual can benefit from this help beyond the immediate tasks and backgrounds in order to meet new conditions. Then ZPD can be defined as "the distance between the current level of development without help and the potential level of development that is established through guidance" (Dorfler, Golke, \& Artlet, 2009, p.77). Williams and Burden (1997) state that DA is a process where "assessment and learning are seen as inevitably linked and not separate." Lidz and Gindis (2003, p.99) indicate that DA is an "approach to understanding individual differences and their implications for instruction that embeds intervention within the assessment procedure." In the opinion of Haywood and Lidz (2007) DA is "an interactive approach to conducting assessments that focuses on the ability of the learner to respond to intervention." Lussier and Swanson (2005) define dynamic assessment as a "procedure that attempts to modify performance, via examiners' assistance, in an effort to understand learning potential" (p. 66) Lidz (1991) defines dynamic assessment as "an approach that follows a test-intervene-retest format, and that focuses on learner modifiability and on producing suggestions for interventions that appear successful in facilitating improved learner performance" (p. 6). Poehner (2008) has provided the following definition:

active collaboration with individuals simultaneously reveals the full range of their abilities and promotes their development. In educational contexts, this means that assessment (understanding learners' abilities) and instruction (supporting learner development) are a dialectically integrated activity. This pedagogical approach has come to be known as Dynamic Assessment. (p.2)

The main feature characterizing the Zone of Proximal Development of a learner is the concept of modifiability (Kozulin \& Garb, 2001; Lidz \& Elliott, 2000). DA considers that any assessment must include a description of the extent to which an individual's performance is easily modifiable. The extent of modifiability is an indicator of personal ZPD and is an indicator of potential personal learning ability in the future. However, the key issue for modifiability is its stabili- 
ty. Changing the stability of a behavior is a key determinant of learner's future development. Part of the learning process can actually be done in recent (emerging) areas of development if the performance of the corrections is stable enough, that is, what learners can do today with aid and assistance, they are more likely to do without help in the future. In ZPD, the goal is to determine the amount of change that may be triggered when interacting with more capable peers during the assessment (Bavali et al., 2011). Lantolf and Poehner (2004) proposed two terms, interventionist and interactionist, to explain two general mediations that DA practitioners can follow. Interactionist DA is in line with Vygotsky's cooperative dialogue preferences. In this way, the interaction between the mediator and the learner is helpful and therefore very sensitive to the individual's ZPD. On the other hand, interventionist DA is more akin to some form of static assessment that focuses on the psychological characteristics of its procedures. Interventionist DA provide easily quantifiable results using pre-determined administration procedures and scaffolding forms that can be used to compare between groups and within groups and can be compared with other measurements and used to predict the performance of future tests. Interventionist DA is related to quantifying as an "indicator of learning speed" (Brown \& Ferrara, 1985), which learners need to reach their intended goals quickly and effectively. On the other hand, the interactionist DA emphasizes the development of individual learners and even a group of learners, no matter how much effort is required without concern for predetermined endpoints (Poehner, 2008).

\section{LITERATURE REVIEW}

Poehner (2009) argues that social mediation and engagement in a class context should be studied under a new framework that can be called a group dynamic assessment (G-DA), while group DA and one-to-one DA use the same axiom of providing learners with mediation to support their co-construction of a ZPD, but they are different because the G-DA must consider the group's ZPD. SCT practitioners agree that mediators can work together in a group of individual learners to build a ZPD (Poehner, 2009; Poehner \& Lantolf, 2005). Vygotsky (1998) also recognizes the hypothesis that DA can be used to improve many ZPDs, describing ZPD as "the best time to teach ZPDs to groups and individuals." Aljaafreh and Lantolf (1994) conducted a seminal study in which a mediator collaborated with three learners in an attempt to produce grammatical features such as the use of tense, modal verbs, prepositions and articles in their composition. Mediators met them individually in the writing class and made changes to their previous work. The revision was based on the regulatory scale, the regulatory scale from the most implicit into the most explicit. Poehner (2005) rightly points out that although Aljaafreh and Lantolf (1994) did not have a specific framework for DA research, it is possible to consider research within the DA as the mediators attempt to build ZPD learners to interact with them to diagnose difficult areas and help them gain control of the structure. In another study, Nassaji and Swain (2000) followed Aljaafreh and Lantolf (1994) studies to find out if ZPD-sensitive mediation is necessary to improve performance or whether there is any kind of mediation that is sufficient to help learners progress independently. They were also interested in knowing which mediation promote development more effectively. So, they paired a mediator with two ESL learners. For one of them the mediation was ZPD-sensitive, and for the other it is random, i.e., there was no attempt to adjust the level of assistance to the learners' responsiveness. The results showed that in the independent production of the initial composition, the one that received ZPD sensitivity was actually less accurate, but showed greater improvement due to the mediation provided, surpassing non-ZPD students in the final combination of tasks. Kozulin and Garb (2001) adopted DA interventionist approach, including pre-test and post-test formats. The results showed that DA had a significant effect on improving learners' reading comprehension. Although Poehner (2005) objected to the dynamic nature of the Kozulin and Garb studies, the study clearly fell within the DA framework, although this is apparently the case in the area of interventionist side of the continuum.

In another study by Poehner (2005), the research focused on learners' verbal abilities. Six French secondary students were asked to verbally construct a series of French narratives in short video. Learners had to create the first narrative independently, and in the second narrative they had been given some assistance. The results of these two narratives were used to develop a personalized teaching program. The instructions were followed to assess participants' learning by repeating the original assessment tasks and introducing some newly developed but similar tasks. According to Poehner, "the results of the survey showed that DA is an effective way to understand learners' abilities and help them to overcome language problems, and this approach was particularly relevant to the L2 classroom and was a more systematic method of formative assessment practice". Ableeva (2008) also used DA for college students who were learning French. Her aim was to promote the development of listening comprehension skills, reveal learner differences in exams, reveal their unique ZPDs, which are not revealed in non-predictive context. According to her, implementing DA in reading and listening comprehension classes allows learners and teachers to identify potential sources of problems that may prevent the text from being understood. Another study investigated the effect of DA on improving the listening comprehension of French-speaking students as a foreign language and compared the results with traditional listening comprehension tests. The results showed that the DA spelled out the poor source of performance hidden in traditional assessments. The results also showed that through interaction in ZPD, DA not only establishes the actual level of learner's listening ability, but also identifies and assesses their potential development while contributing to this development. Anton (2003) implemented a dynamic assessment of the placement of L2 Spanish undergraduates. She clarified that dynamic assessment is more accurate for the purpose of placement because it reveals the emerging skills of students rather than just focusing on developing skills through non-dynamic assessments. She believes that implementing a dynamic assessment process 
makes placement more reliable because it provides a more complete description of competencies. As a result, potential significant differences between learners become evident, supporting evidence of the effectiveness of dynamic assessments. Anton asked her research participants to verbally narrate the movie they were watching, mainly focusing on the correct use of the past tense in the narrative. Using an interactionist approach, she interrupts the narrative and offers mediational hints and guidance at any time, giving them the opportunity to change their performance in an acceptable manner. The researchers provided an interesting and useful section of the agreement that clearly demonstrated what happened during the assessment session. In another study, Anton (2009) also studied the efficacy of DA in college students. She used the DA and third-year Spanish specializations in the speech and writing sections of the diagnostic tests. She concluded that DA had a deeper understanding of the student's abilities. Birjandi, Daftarifard and Lange (2011) examined the possibility of distinguishing the quantitative and qualitative impact of dynamic assessments on questions and persons. They used two types of Rasch scaling to scale the Wh-type questions and scan the collection of items. Data collected from 42 Iranian students showed that learners' performance in post-test predictive quantitative improvement relative to wh-pre-testing and scanning programs. However, no tangible qualitative effect was observed because the project and staffing levels were roughly the same before and after testing.

The development of a rating criterion is a useful indicator of ZPD as it proves to be an appropriate tool for collecting pre-test and post-test data. Xiaoxiao and Yan (2010) provided a simple framework or process for teaching English writing based on the principles of dynamic assessment. Their findings showed that the teaching of dialogue is very helpful for improving learners' writing interest and writing ability.

In another study, Sadeghi and Khanahmadi (2011) studied dynamic assessment as a means of promoting linguistic knowledge of EFL learners in Iran. The study was conducted on 60 intermediate English learners. During the course of treatment, the experimental group and the control group were tested for grammar, in which the experimental group received the mediation on the test items. Their findings showed that the dynamic assessment instruction significantly enhanced the English language learners' knowledge of the language. In another study on dynamic assessment of reading comprehension, Naeni and Duvall (2012) used a mixed-methods approach to assessing 10 undergraduates to improve reading comprehension performance. Their research phase consisted of three phases, each of which included three specific reading comprehension sub-skills and the meaning of finding unknown words. Their research found significant development of reading comprehension performance after DA-oriented mediation.

Although a considerable body of research has been carried out on the applicability of DA in language classroom settings, very little is known about the effect of implementation of DA in teaching EFL grammar in a classroom context.

\section{Objective and Research Question}

This study is an attempt to shed some light on the effectiveness of DA on EFL learners' L2 grammar development. To this end, the following research question was formulated:

- Does classroom DA has an effect on the development of L2 grammar knowledge?

\section{METHOD}

\section{Design}

The present study adopts a quasi-experimental design with an experimental and a control group. The members of both groups initially took a non-dynamic pre-test of the target structure to ensure the unfamiliarity of the target structure to the participants. The participants in the experimental group received grammar instruction through DA, while the control group members received conventional grammar instruction on the target structure. After four sessions of instruction for each group, all participants took a dynamic post-test followed by a non-dynamic delayed post-test, which was administered two weeks later (Figure 1).

\section{Participants}

Participants of the present study were 46 male English as a foreign Language (EFL) intermediate students of a major language institute in Shiraz, Iran. Gender was considered a control variable in this study. Their ages ranged from 15 to 20 and they all came from the same sociocultural background. They all spoke Farsi as their first language and had completed 2 years of English education at the institute. Based on the results of the institute's language placement test as well as their levels of the EFL courses in which they had enrolled, they were considered to be intermediate learners. They were members of two intact classes each consisting of 23 students.

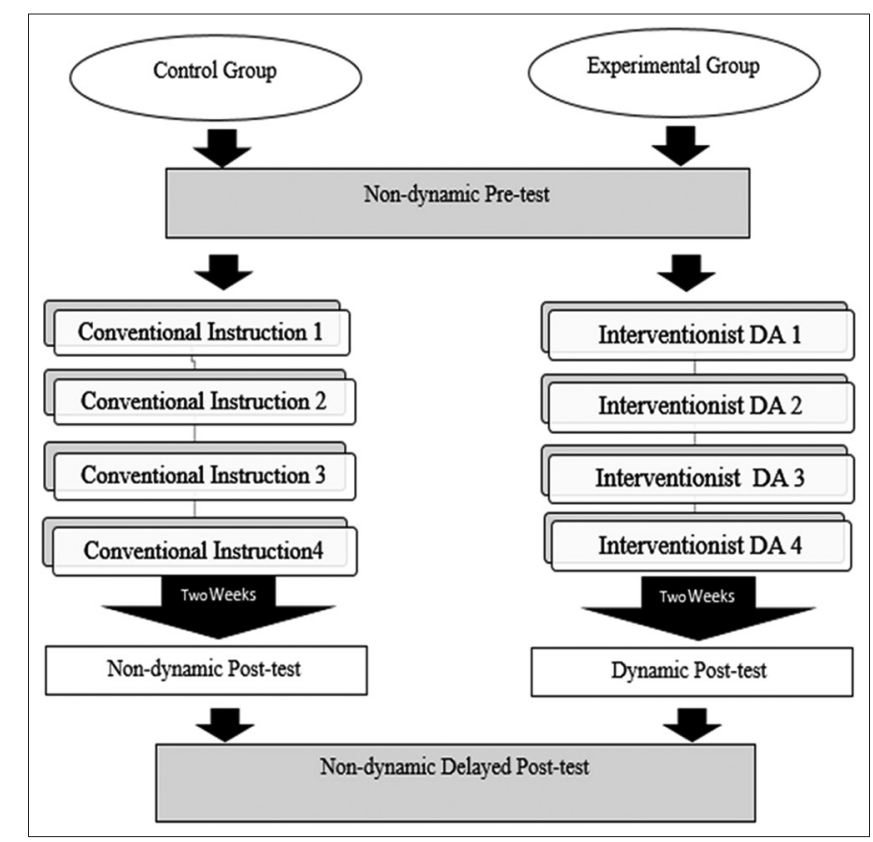

Figure 1. Design of the study 


\section{Target Structure}

In the current study, the unreal conditional in English, also known as hypothetical conditional (for example, if I had wings, I would fly) was chosen as the target structure. Teachers and researchers agreed that unreal conditionals are one of the most difficult structures for L1 and L2 learners (Covitt, 1976, cited by Celce-Murcia \& Larsen-Freeman, 1999; López Ornat, 1994, cited by Rosa \& Leow, 2004). Because this structure is quite difficult for the participants to learn, only the present unreal conditionals were chosen as the target structure rather than the past one (for example, if I had wings, I would fly to you instead of if I had wings, I would have flown to you).

\section{Procedure}

To ensure that learners were not familiar with the target structure, i.e., unreal present conditional, a written grammaticality judgement task of unreal conditional with 20 items was administered, in which learners were asked to choose the correct unreal conditional statements in affirmative sentences. One of the intact classes was assigned as the control group, to receive conventional grammar instruction on the target structure, and the other class as the experimental group to receive DA on the target structure. The instruction was delivered in 4 sessions for each of the groups during two weeks. Each session lasted an hour and forty-five minutes. In teaching the target structure to the experimental group, the researcher applied ZPD-sensitive mediations and hints from the most implicit to the most explicit ones. The researcher provided the learners with the most implicit hints and went through the most explicit mediations in case learners could not produce accurate sentences with the target structure. This can be illustrated in the following Regulatory Scale.

Regulatory Scale of DA Mediations for L2 Grammar Instruction of Conditional Type II

1. Indication of a mistake in learner's utterance

2. Narrowing down to the erroneous part

3. Asking the learner if they are talking about something that can happen now or something that cannot happen now/is impossible

4. Contextualization of the target structure using examples

5. Providing the correct utterance

Unlike instruction for the experimental group, the control group was taught the target structure conventionally, and in case learners encountered problems in producing accurate sentences with the target structure, the researcher did not offer any mediations and provided the correct sentence.

\section{Instruments}

To collect numerical data, i.e. grammar scores on three different occasions, one grammar pre-test and two grammar post-tests (an immediate and a delayed) was used. A written grammaticality judgement test of English conditional type II sentences comprising 20 multiple choice items was used. As to the materials which were used in this study, the Iran Language Institute's English Series (Intermediate 1) (Iran
Language Institute, 2006) was the major course book used by the researchers for instruction of the target structure to the participants since it was their course book at the institute.

\section{Data Analysis}

Data were keyed in to SPSS (Version 22) for descriptive and inferential statistical analyses. Descriptive statistics included mean and standard deviation, and inferential statistics includes multivariate analysis of covariance.

The homogeneity of dependent variable covariance matrixes in both control and experimental groups was checked using Box's $M$ test (Box's $\mathrm{M}=2.637, \mathrm{~F}=.836, \mathrm{df}=3.348$, $\mathrm{p}=0.474)$.

As the Shapiro-Wilk's test results $(\mathrm{p}>0.05)$ in Table 1 show, the dependent variable data were normally distributed. The descriptive statistics results for non-dynamic pre-test, dynamic and non-dynamic post-tests, and non-dynamic delayed post-test are presented in Table 2 .

To investigate the effectiveness of dynamic assessment on learning Conditional Type II structure in English by EFL learners, multivariate analysis of covariance was run. As displayed in Table 3, Pillai's Trace (0.712) for group factor is statistically significant $(p<0.05)$. As a result, there is a significant difference between control and experimental groups in grammar test. The effect size is 71.2 in partial eta square. Consequently, group factor determines 71.2 percent of variance in dependent variables. Pillai's Trace $(0.131)$ for pre-test scores is statistically significant $(\mathrm{p}<0.01)$. Therefore, the administration of pre-test has been effective in this study. The effect size is 13.1 in partial eta square. Therefore, pre-test scores determine 13.1 percent of variance in dependent variables.

Tests of Between-Subjects Effects (Table 4) analyze each dependent variable separately. The effect of group factor on the dependent variable (scores on post-tests) is statistically significant $(\mathrm{F}(1.43)=106.15, \mathrm{p}<0.05)$. Therefore, post-test scores between control and experimental groups are statistically significant. It can be concluded that DA has been effective in learning L2 grammar. The effect size is 71.2 in partial eta square, and 71.2 percent of variance in the dependent variable (scores on post-tests) is determined by group factor. The effect of pre-test scores on dependent variable is statistically significant at $\mathrm{p}<0.05, \mathrm{~F}(1.43)=6.48$. Therefore, the administration of pre-test has been effective in investigating the effectiveness of instruction. The effect size is 13.1 percent. As a result, pre-test scores determine 13.1 percent of variance in the dependent variable (post-test scores). The effect of group factor on the dependent variable is statistically significant. Therefore, the positive effect of DA in promoting L2 grammar acquisition is confirmed. The effect size in partial eta square is 61.9 percent, indicating that 61.9 percent of variance in the delayed post-test scores is determined by group factor. The effect of pre-test on the dependent variable is statistically significant at $\mathrm{p}<0.05, \mathrm{~F}(1.43)=3.88$, indicating the fact that the administration of pre-test has been effective in investigating the sustainability of the effectiveness of DA instruction. The effect size in partial eta square is 8.3 percent, pointing to the fact that pre-test scores determine 8.3 percent of variance in scores of the delayed post-test. 
Table 1. Tests of Normality

\begin{tabular}{llcccccc}
\hline Group & & \multicolumn{2}{c}{ Kolmogorov-Smirnov } & \multicolumn{3}{c}{ Shapiro-Wilk } \\
\cline { 3 - 7 } & & Statistic & df & Sig. & Statistic & df & Sig. \\
\hline N-D- N-D-Post & 1 Control & 0.133 & 23 & 0.200 & 0.952 & 23 & 0.327 \\
& 2 Experimental & 0.155 & 23 & 0.162 & 0.938 & 23 & 0.160 \\
N-D-Delayed & 1 Control & 0.100 & 23 & 0.200 & 0.957 & 23 & 0.410 \\
& 2 Experimental & 0.158 & 23 & 0.144 & 0.962 & 23 & 0.510 \\
\hline
\end{tabular}

Table 2. Descriptive Statistics for Pre-Test, Post-Test, and Delayed Post-Test Scores

\begin{tabular}{llcccccc}
\hline Variable & Test & \multicolumn{3}{c}{ Group } \\
\cline { 3 - 7 } & & \multicolumn{3}{c}{ Control } & \multicolumn{3}{c}{ Experimental } \\
\cline { 3 - 7 } & & Mean & SD & Sample Size & Mean & SD & Sample Size \\
\hline Grammar Scores & Pre-test & 2.30 & 1.96 & 23 & 2.43 & 1.90 & 23 \\
& Post-test & 11.87 & 2.42 & 23 & 17.04 & 1.64 & 23 \\
& Delayed & 10.30 & 2.32 & 23 & 15.30 & 1.79 & 23 \\
& Post-test & & & & & & \\
\hline
\end{tabular}

Table 3. Results of Multivariate Analysis of Covariance

\begin{tabular}{llcccccc}
\hline Trace & Test Method & Statistic Value & F Value & Hypothesis df & Error df & P & Partial Eta Squared \\
\hline Group & Pillai's Trace & 0.712 & 51.86 & 2 & 42 & 0.000 & 0.712 \\
& Wilks' Lambada & 0.288 & 51.86 & 2 & 42 & 0.000 & 0.712 \\
& Hotelling's Trace & 2.47 & 51.86 & 2 & 42 & 0.000 & 0.712 \\
& Roy's Largest Root & 2.47 & 51.86 & 2 & 42 & 0.000 & 0.712 \\
\multirow{3}{*}{ Pre-test Scores } & Pillai's Trace & 0.131 & 3.17 & 2 & 42 & 0.131 & 0.131 \\
& Wilks' Lambada & 0.869 & 3.17 & 2 & 42 & 0.869 & 0.131 \\
& Hotelling's Trace & 0.151 & 3.17 & 2 & 42 & 0.151 & 0.131 \\
& Roy's Largest & 0.151 & 3.17 & 2 & 42 & 0.151 & 0.131 \\
& Root & & & & & & \\
\hline
\end{tabular}

Table 4. Tests of Between-Subjects Effects

\begin{tabular}{llcccccc}
\hline Dependent Variable & $\begin{array}{l}\text { Source of } \\
\text { Variance }\end{array}$ & $\begin{array}{c}\text { Sum of } \\
\text { Squares }\end{array}$ & $\begin{array}{c}\text { Degree of } \\
\text { Freedom }\end{array}$ & Mean of Squares & F & P & Partial Eta Square \\
\hline Post-test Scores & Group & 333.57 & 1 & 333.57 & 106.15 & 0.000 & 0.712 \\
& Pre-test & 20.35 & 1 & 20.35 & 6.48 & 0.015 & 0.131 \\
& Error & 135.12 & 43 & 3.14 & & & 0.619 \\
Delayed Post-test Scores & Group & 282.55 & 1 & 282.55 & 69.81 & 0.000 & 0.083 \\
& Pre-test & 15.70 & 1 & 15.70 & 3.88 & 0.045 & \\
& Error & 174.04 & 43 & 4.05 & & & \\
\hline
\end{tabular}

\section{DISCUSSION AND CONCLUSION}

The present study aimed to investigate the possible impact of classroom DA on the development of L2 grammar knowledge by EFL learners. The findings of this study indicated that learners who received ZPD-sensitive mediations according to the Regulatory Scale used in this study significantly outperformed the learners in the control group both on dynamic post-test and non-dynamic delayed post-test of the target structure. This can be attributed to the fact that learners' actual scores, i.e., scores obtained from a non-dynamic grammar test in which learners are required to provide answers to questions with no assistance, or in terms of Sociocultural Theory, scaffolded feedback, do not represent their full potential in learning L2 grammar knowledge. The same learners could have internalized L2 grammar knowledge and scored higher had they been provided with scaffolded feedback. Aljaafreh and Lantolf (1994) characterize three characteristics for scaffolded feedback: a) It ought to be graduated with no more help than is needed; b) it should be contingent on the needs of 
learners; and c) it should be dialogic, with both the learner and the interlocutor.

According to sociocultural theory, interaction is not only conducive to language learning, but also an incentive for the acquisition. Moreover, all learning is viewed as a social process based on socio-cultural backgrounds. Another concept related to socio-cultural theory, known as the ZPD, is defined as the distance between the level of actual development determined by independent problem-solving and the potential level of development determined by problem-solving under adult assistance or in collaboration with more competent peers. This means that learning is the result of interpersonal activities and it is the interpersonal activities that form the basis of individual functioning. This clearly demonstrates the social nature of learning, highlighting the significance of collaborative learning as it forms what has been learned.

The concept of mediation is of great significance in the sociocultural theory. Sociocultural theory is based on the assumption that human activities are mediated by the socalled symbolic artifacts (higher-level cultural tools) such as language and culture and material artifacts. These artifacts mediate the relationship between humans and the social and material world around us. In socio-cultural theory, humans use symbols as a tool to mediate psychological activity and control mental processes. This control is voluntary, allowing us to pay attention to certain things, to planning and to rational thinking. The main tool humans can use is language, which is the tool that enables us to connect to our environment (physical and social). Language empowers humankind to go beyond the immediate environment, thinking and talking about events and objects that are far removed both physically and temporally (Tavakoli, 2012).

The findings of this study also point to the advantage of the implementation of DA in teaching L2 grammar. This refers to the fact that knowledge of L2 grammar is not categorical, i.e., one cannot claim that a learner either knows an L2 structure or (s)he does not, since L2 grammar acquisition has been shown to be a developmental process and learners go through different stages of development before they master an L2 target structure. Consequently, language teachers will do a better job if they provide $\mathrm{ZPD}$-sensitive mediations during L2 grammar instruction.

This, in turn, has implications for language assessment. Most L2 grammar tests that are currently being used only gauge learners' current or actual level of performance without any concern for learners' potential performance, or what learners can do with assistance. Some learners require fewer mediations while some others need more mediations to perform the same task. This can be attributed to the differential ZPDs that learners possess in carrying out a certain task. If language testers provide ZPD-sensitive mediations to test-takers during assessing their performances, they can not only obtain actual scores based on testers current level of ability but also capture test-takers potential scores, which are often ignored, and thus have a more complete picture of test-takers' performances.

There are some limitations to this study which should be acknowledged. First, this study adopted the interventionist approach to DA, which limits the flexibility and types of mediations that could be provided by the researcher. Applying the interactionist approach to DA can result in more appropriate and tailored mediational hints, as teachers have latitude in individualizing DA procedures. Second, the effect of other variables such as gender, proficiency level, and individual learner differences on the effectiveness of DA could not be included in this study due to logistical issues. It would be a worthwhile topic to be investigated by interested researchers. In addition, mixed method research in the implementation of DA seems to provide a better picture of learners' L2 grammar development over time as both quantitative and qualitative data can increase the validity of the results.

\section{REFERENCES}

Ableeva, R. (2008). The effects of dynamic assessment on L2 listening comprehension. In J. P. Lantolf, \& M. E. Poehner (Eds.), Sociocultural theory and the teaching of second languages (pp. 57-86). London: Equinox.

Ableeva, R. (2010). Dynamic assessment of listening comprehension in second language learning. (Unpublished Doctoral Dissertation), The Pennsylvania State University.

Aljaafreh, R., \& Lantolf, J. P. (1994). Negative feedback as regulation and second language learning in the zone of proximal development. The Modern Language Journal, $78,436-483$.

Anton, M. (2003). Dynamic assessment of advanced foreign language learners. Paper presented at the American Association of Applied Linguistics, Washington, D. C.

Anton, M. (2009). Dynamic assessment of advanced second language learners. Foreign Language Annals, 42(3), 576-598.

Bavali, M., Yamini, M., \& Sadighi, F. (2011). Dynamic Assessment in Perspective: Demarcating Dynamic and Non-dynamic Boundaries. Journal of Language Teaching and Research, 2(4), 895-902. doi:10.4304/j1tr.2.4

Birjandi, P., Daftarifard, P., \& Lange, R. (2011). The effects of dynamic assessment on Rasch item and person hierarchies in second language testing. International Journal of Language Studies, 5, 125-140.

Brown, A., \& Ferrara, R. A. (1985). Diagnosing zones of proximal development. In J.V. Wertsch (Ed.), Culture, Communication and Cognition. Vygotskian Perspectives (p. 300). Cambridge: Cambridge University Press.

Celce-Murcia, M., \& Larsen Freeman, D. (1999). The grammar book: An ESL/EFL teacher's course ( $2^{\text {nd }}$ ed.). Boston, MA: Heinlle \& Heinle.

Dorfler, T., Golke, S., \& Artlet, C. (2009). Dynamic assessment and its potential for the assessment of reading competence. Studies in Educational Evaluation, 35, 77-82.

Haywood, H. C., \& Lidz, S. C. (2007). Dynamic assessment in practice: Clinical and educational applications. Camridge: Camridge University Press.

Iran Language Institue (2006). The ILI English Series: Intermediate 1 student's book, Tehran: Kanoonchap.

Kozulin, A., \& Garb, E. (2001). Dynamic assessment of EFL text comprehension of at-risk students. School Psychology International, 23, 112-127. 
Lantolf, J. P., \& Poehner, M. E. (2004). Dynamic assessment of L2 development: bringing the past into the future. Journal of Applied Linguistics, 1, 49-72.

Lidz, C., \& Elliott, J. (2000). Dynamic assessment: prevailing models and applications. Advances in cognition and educational practice, 6, Elsevier Science Inc.

Lidz, C. S. (1991). Practitioner's guide to dynamic assessment. New York: Guilford

Lidz, C. S., \& Gindis, B. (2003). Dynamic assessment of the evolving cognitive functions in children. In A. Kozulin, B. Gindis, V. S. Ageyev, \& S. M. Miller(Eds.). Vygotsky's educational theory in cultural context.

Luria, A. R. (1961). Study of the abnormal child. American Journal of Orthopsychiatry: A Journal of Human Behavior, 31, 1-16.

Lussier, C. M., \& Swanson, H. L. (2005). Dynamic assessment: A selective synthesis of the experimental literature.In G. M. van der Aalsvoort, W. C. M. Resting, \& A. J. J. M. Ruijssenaars (eds.). Learning potential assessment and cognitive training: Actual research and perspectives in theory building and methodology, New York: Elsevier, 65-87.

Naeni, J., \& Duvall, E. (2012). Dynamic assessment and the impact on English language learners' reading comprehension performance. Language Testing in Asia, 2(2), 1-22.

Nassaji, H., \& Swain, M. (2000). A Vygotskian perspective on corrective feedback in L2: The effect of random versus negotiated help on the learning of English articles Language Awareness, 9, 503-517.
Poehner, M. E. (2005). Dynamic assessment of oral proficiency among advanced L2 learners of French. (Unpublished Doctoral Dissertation), The Pennsylvania State University.

Poehner, M. E. (2008). Dynamic assessment: A Vygotskian approach to understanding and promoting L2 development. US: Springer.

Poehner, M. E. (2009). Group dynamic assessment: Mediation for the L2 classroom. TESOL Quarterly, 43(3), 471-491.

Rosa, E., \& Leow, R. P. (2004). Awareness, different learning conditions, and second language development. Applied Psycholinguistics, 25, 269-292.

Sadeghi, K., \& Khanahmadi, F. (2011). Dynamic assessment of L2 grammar of Iranian EFL learners: The role of mediated learning experience. International Journal of Academic Research, 3(2), 931-936.

Tavakoli, H. (2012). A Dictionary of Language Acquisition. Tehran: Rahnama Press.

Vygotsky, L. S. (1962). Thought and language. Cambridge, MA: MIT Press.

Williams, M., \& Burden, L. R. (1997). Psychology for language teachers: A social constructivist approach. Cambridge: Cambridge University Press

Xiaoxiao, L., \& Yan, L. (2010). A case study of dynamic assessment in EFL process writing. Chinese Journal of Applied Linguistis, 33(1), 24-40. 